
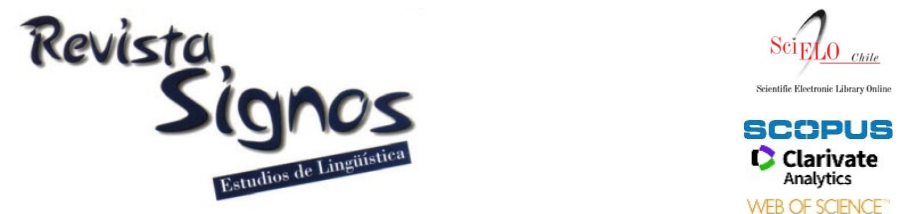

\title{
The effect of visual priming on the lexical retrieval on implicit memory tasks for advanced foreign language learners
}

\section{El efecto priming en la recuperación léxica en tareas de memoria implicita para estudiantes avanzados de idiomas extranjeros}

\author{
Mohammad Saber Khaghaninejad \\ SHIRAZ UNIVERSITY \\ IRAN \\ saber.khaghani@yahoo.com
}

\author{
Bahareh Farrokhiyekta \\ SHIRAZ UNIVERSITY \\ IRAN \\ baharehfy@yahoo.co.uk
}

Recibido: 03-IV-2018 / Aceptado: 18-I-2019

DOI: $10.4067 /$ S0718-09342020000100104

\begin{abstract}
This study investigated the possible effects of visual priming on a foreign language vocabulary retrieval on three implicit memory task types (i.e., word stem completion (WSC), word fragment completion (WFC) and anagram solution tasks). Gender effect was also focused for lexical retrieval under the priming effect. A total of 45 male and 45 female Iranian advanced EFL learners were recruited and assigned to each of the three experimental groups of the study which contained an equal number of males and females learners. WSC, WFC and anagram solution tasks held 30 lexical items which were developed out of 5000 most frequent words in English. 15 primed and 15 unprimed lexical items were randomly accommodated in each task. After the visual priming phase and distracting participants' attention via an unrelated task, the participants were asked to do the implicit memory tasks according to their experimental groups. The results showed that participants gained higher scores on the visually primed lexical items on all implicit tasks (the maximum improvement for anagram solution task and the minimum for WFC). Also, no statistically significant difference was observed between males and females regarding their performance on implicit memory tasks under the visual priming effect.
\end{abstract}

Key Words: Visual priming, Implicit memory tasks, Lexical retrieval, Foreign language learning. 


\section{Resumen}

Este estudio investigó los posibles efectos del priming visual en la recuperación de vocabulario en un idioma extranjero en tres tipos de tareas de memoria implícita (es decir, tareas de completar raíces (WSC), tareas de completar fragmentos (WFC) y tareas de solución de anagramas). El efecto de género también se enfocó para la recuperación léxica bajo el efecto priming. Un total de 45 hombres y 45 mujeres estudiantes iraníes de EFL avanzados fueron reclutados y asignados a cada uno de los tres grupos experimentales del estudio que contenía un número igual de estudiantes hombres y mujeres. Las tareas de solución WSC, WFC y anagramas contenían 30 elementos léxicos que se desarrollaron de las 5000 palabras más frecuentes en inglés. En cada tarea se alojaron al azar 15 elementos léxicos imprimados y 15 no imprimados. Después de la fase de preparación visual y la distracción de los participantes a través de una tarea no relacionada, se les pidió a los participantes que realizaran las tareas de memoria implícita de acuerdo con sus grupos experimentales. Los resultados mostraron que los participantes obtuvieron puntuaciones más altas en los ítems léxicos visualmente preparados en todas las tareas implícitas (la mejora máxima para la tarea de solución de anagramas y el mínimo para WFC). Además, no se observaron diferencias estadísticamente significativas entre hombres y mujeres con respecto a su desempeño en tareas de memoria implícita bajo el efecto priming.

Palabras Clave: Priming visual, Tareas de memoria implícita, Recuperación léxica, Aprendizaje de idiomas extranjeros.

\section{INTRODUCTION}

Priming method is one of the most popular experimental techniques to be found in psycholinguistics (Harley, 2009) which has only recently turned into one of the realms of EFL studies (Shen, 2015; Jiang \& Huang, 2015; Dawei, Jinbo \& Heping, 2016). Priming studies have shown that there is a reduction in neural activity when the subjects are exposed to target or the repeated stimulus as compared to their first encounter (Henson \& Rugg, 2003); consequently, vocabulary acquisition, a significant area of foreign language learning, might be enhanced through lexical priming which is the focus of the present study.

A linguistically-acceptable description of priming can be "an implicit process in which language production or comprehension is influenced by prior exposure to certain forms or meanings" (Trofimovich \& McDonough, 2011: 12). As priming is implicit in nature, priming studies are in fact part of implicit memory research studies. Implicit memory is automatic and procedural and is related to the unconscious effect of prior information on the behavior that would follow (Cleeremans, 2009). Implicit memory embraces different kinds of learning such as repetition priming, procedural learning and classical conditioning (Cervantes \& Granados Ramos, 2015). Priming is an unconscious phenomenon in which prior experience influences reaction to a stimulus (Gulan \& Valerjev, 2010). Therefore, it is possible to compare priming to 
stimulus-response conditioning, although in this case, exposure to some stimulus or the prime will lead to a certain reaction to a second prime which is called target. The time interval between presentation of the prime and the target is called stimulus onset asynchrony or briefly SOA (Harley, 2009). This stimulus can take verbal, auditory or visual form.

Many researchers claimed that neither intentional vocabulary learning is more effective than the incidental methods, nor the incidental learning is necessarily more conducive to more successful language learning (e.g., Brown, Waring \& Donkaewbua, 2008). This means that both the implicit and the explicit methods of learning and teaching should be embraced as they go hand in hand in the context of foreign language teaching and learning for the two together can create a unique productive synergistic learning and teaching experience. Therefore, stimulating learners' implicit retrieval of vocabulary items through priming which acts as a supplement to the explicit and more traditional methods, can contribute its share to the realm of language learning and teaching.

This study aimed at scrutinizing the visual priming effects to see if previous encounters can encourage language learners to retrieve the same L2 items in the case of necessity. Moreover, it tried to make a comparison between the performances of the participants on three different implicit memory tasks to see which task under focus has been more likely to be affected by visual priming technique. Additionally, the study has focused on the gender differences of Iranian advanced EFL learners on different implicit memory task types; this study has been a systematic attempt to answer the following research questions:

- Does visual priming significantly affect the retrieval of lexical items for advanced EFL learners?

- Which one of the implicit memory tasks (i.e., word fragment completion, word stem completion and anagram solution) would be more affected by visual priming?

- Do male and female advanced English learners have different performances on implicit memory tasks for the primed lexical items?

\section{Literature review}

According to Trofimovich and McDonough (2011), Cattell (1886) was probably among the first researchers to observe priming phenomenon. Some decades later, Segal and Cofer (1960) pragmatically introduced the priming effect and indicated that language users are more likely to use words they have previously been exposed to. Later, Meyer and Schavenveldt (1971) conducting a study in the realm of cognitive psychology, revealed that reaction time to semantically-related pairs was around 85 milliseconds faster than the reaction time to unrelated word pairs. In fact they 
concluded that a word would be recognized faster if it has been preceded by a semantically-related word.

Trofimovich and McDonough (2011) enumerated three types of priming, namely 'syntactic', 'auditory' and 'semantic'; syntactic priming means that exposure to a certain syntactic structure might lead to production of language containing that same primed structure. Auditory priming means that exposure to the auditory form of a word in a conversation will make that word faster and easier to process in the next encounter. Semantic priming is the tendency for language users to more accurately and more quickly process the target word when they have a previous exposure to another word which is semantically related. As a typical example, when the word cat is primed, the word dog will be activated in the mind of the speaker because the two are related in meaning.

Visual priming of a lexical item is done by presentation of the prime item followed by repetition of that item days, weeks or minutes later (Masson, 2001). Of course according to Oschner, Chiu, and Schacter (1994), visual priming has a fundamental difference with explicit and conscious remembering in terms of mental processes involved. The memory system which supports repetition priming is different from the memory system which supports explicit memory. Visual priming, in fact, much depends on the perceptual way of representation dealing with physical features, structure and form and not the associative and semantic features. The fact that visual priming effect could last for hours or even for weeks is what distinguishes it from other priming types such as semantic priming that could only last for seconds.

According to Schacter (1987), implicit memory tasks are defined as tasks that do not need respondents to consciously recollect the study episode in order for them to complete the task successfully, although their performance is influenced by the previous episode. As priming is indirect in nature, it can only be inferred based on performance on implicit memory tasks (Lorenzi, Giunta \& Di Stefano, 2006). Implicit association test (IAT), category-instance generation task, lexical decision task (LDT), word fragment completion (WFC), word stem completion (WSC) and anagram solution are among the widely-used implicit memory tasks.

Perruchet and Baveaux (1989), in a study compared a number of implicit tasks. The participants had to study 120 words and then four implicit and two explicit tests were used to measure their performance with 20 different words for each task. Perceptual clarification and recall were the two explicit tests used and the implicit tests were word fragment completion, anagram solution, word identification and recognition. A positive correlation was reported among recognition, word fragment completion, perceptual clarification and recall. However, although there was a positive correlation between anagram solution and word identification, the two were reported to be unrelated to other tasks. 
Srinivas and Roediger (1990), in order to investigate priming modalities, compared three implicit tests of memory including anagram solution, word fragment completion and category association in latter case the participants did not refer to word lists. The results indicated that the first two tests were more or less similar. In both cases, the largest priming effect was reported for the visually presented words, small priming effect from auditory presented words and no priming from pictorial mode of presentation. Category association, on the other hand, was not affected by modality and it acted like free recall. The results indicated that implicit tests could be dissociated from one another.

\subsection{Priming in foreign language teaching and learning}

More recently, some researchers have investigated effects of priming on acquiring different aspects of a foreign language. Some of the studies available, focus on vocabulary and some others focus on grammar. Also some of these studies are concerned with the modality of priming which could either be done pictorially, auditorily or by visually presenting the words. What is obvious is that it is not a long time since priming has paved its way into EFL studies although some claim that the first priming study in the EFL context could be attributed to Cattell (1886) by his discovery of semantic priming (Harley, 2009). According to Trofimovich and McDonough (2011), however, some aspects of priming have not received much attention and from the existing studies, a few have been detailed and comprehensive. In this regard, McDonough (2006) attested the positive effect of syntactic priming (a speaker's tendency to produce a previously spoken or heard structure) on interaction between L2 English speakers and the development of L2 dative constructions. In another study, McDonough and Mackey (2008) showed the positive effects of structural priming on producing well-formed questions in English for intermediate Thai ESL learners.

One of the priming studies which focused on vocabulary learning was that of Bird and Williams (2002). In that study in which both the native and the non-native English speakers were involved, priming was presented either through single-mode (text or audio) or bi-modally (text and audio) and participants' improvement in their auditory word and non-word recognition was measured through lexical decision and rhyme judgment tasks. The results of lexical decision task for familiar words indicated that auditory priming equally occurred under both formats of presentation. The rhyme judgment task also obtained repetition priming which was greater for the bimodal presentation. This study showed that recognition memory for both words and nonwords could be improved through bi-modal presentation of input which could be implemented in teaching and learning novel vocabulary items.

McDonough and Chaikitmongkol (2010) in another study explored the potential effects of priming in the EFL context for Thai learners. Half of the participants 
followed their regular English curriculum (the control group) while the other half performed priming activities with their peers (the experimental group). After taking the treatment course, experimental participants were found to produce more whquestions with the given auxiliary verbs. Shen (2015) conducted a priming study in the Chinese context for English learners who were reportedly at the same level of proficiency. In the first stage, the participants were given a number of pictures they had to describe. Afterwards they were divided into two groups in which they were received the priming for performing the 'listen and repeat' and 'gap-filling' tasks, both containing relative pronouns and adverbials. The results showed that priming had worked very well for the both tasks, however, it was found to be more influential for the 'gap-filling'task.

Vocabulary learning is one of the biggest challenges foreign language learners encounter during the process of learning a new language. The present study investigated the visual priming effect by use of words in their written forms which were presented as primes. Visual priming was measured under three different testing conditions of WSC, WFC and anagram solution which were perceptual implicit tasks to investigate the influence of priming on the lexical retrieval of Iranian advanced EFL learners of both genders. Using this method as a complementary aid may probably lift some of the burdens of vocabulary teaching and learning from the shoulder of both learners and teachers. Specifically, if visual priming leads to long-term retrieval of lexical items as it is claimed by some researchers (Masson, 2001), it would save much time and energy by making teaching and learning process much more efficient.

Through one of the initial gender-based memory studies, Simotas (1996) discovered that women do benefit from a superior verbal memory while men are privileged with a better visual-spatial memory. There have been very few studies regarding the possible differences of males and females' retrieval of primed lexical items on implicit memory tasks most of which found no noticeable differences between the two genders on performing memory tasks (e.g., Fausto-Sterling, 1985; Halpern, 1992), however, in a different study, Lemm, Dabady and Banaji (2005), conducting a research at Harvard University, suggested the superiority of females in retrieving the orthographically-primed target words over males. They also found male participants superior on implicit memory tasks while primed by the images of the target words.

In a more recent study, Yamada (2015) showed that age and gender as undeniably determining psychological parameters do affect the rate, quality and outcome of priming process in the way that the raise of the age would result in the failure of priming process particularly for those older than 60 . He also found females more successful than males on word decision tasks when primed by the target word visually. Considering the controversial literature concerning the gender-based differences on 
performing memory tasks and the shortage of empirical investigation in this regard, this study attempted to compare the success of the male and the female participants on the implicit memory tasks to check the possible effect of gender on the priming process.

\section{Method}

\subsection{Participants}

This study involved three different experimental groups each containing 30 advanced EFL learners of both genders who were asked to complete one of the implicit memory tasks. The study tried to recruit the participants whose ages ranged from 21 to 30. The participants included 17 Shiraz University B.A senior students of English literature, $45 \mathrm{MA}$ students of TEFL, 21 holding B.A in English literature and 7 with an M.A degree in TEFL from Shiraz University. It should be mentioned that each experimental group contained equal number of males and females. The participants were selected based on convenience sampling selection procedure and the research was conducted by informed consent of participants and their personal information remained confidential based on codes of ethics.

\subsection{Instruments}

This study investigated the effect of visual priming by assessing the performance of participants on three commonly used perceptual implicit memory tests. Since the study dealt with lexical production, the first step required to be taken was to prepare a list of 30 words of 6 to 9 letters selected from 5000 most frequent words which were to be utilized for different phases of the study. As it is explained, these words were manipulated in different manners for meeting the requirements of different implicit memory tasks. Three phases were followed sequentially to achieve the study's purpose: The priming phase, the intervening phase and the assessment phase.

For the priming phase of the study, a Microsoft PowerPoint slideshow was used in which 15 target words were presented visually (the word accompanying with its pictures) as visual prompts in 15 consecutive slides with blank intervals. As the intervening phase of the study, a task which required respondents to provide the names of their first top ten movies as a 15 minute break in order to distract their conscious attention to the priming phase. For the assessment phase of the study, three different measures were employed for the participants:

- WFC task_ The fragments were produced by randomly deleting 3 letters from 6 and 7 letter words and 4 letters from 8 and 9 letter words. For instance, the word 'sweater' when turned into a word fragment item, looked like: s - -at - r. The word fragment task consisted of thirty items, a random mixture of fifteen 'primed' and fifteen 'non-primed' words. 
- WSC task_For word stem completion, the first three letters were maintained as a cue and the rest of the letters were omitted. In this case, the word 'sweater' when turned into a word stem, looked like: swe - - - . The WSC task consisted of thirty items, a random mixture of fifteen 'primed' and fifteen 'non-primed' words.

- Anagram solution task_ Anagrams were in fact a random scramble of the letters in each word, therefore the participants needed to generate a word out of the letters by using all the letters and not using any of the letters given more than once. Taking the previous example, anagram solution task generated out of the word 'sweater' looked like: tersewa. The anagram solution task consisted of thirty items, a random mixture of fifteen 'primed' and fifteen 'non-primed' words.

The following table depicts the words employed for the three implicit memory tasks of the enquiry. The primed ones are underlined.

Table 1. Implicit memory tasks of the study.

\begin{tabular}{|c|c|c|c|}
\hline Vocabulary items & WSC & WFC & Anagram solution \\
\hline sweater & swe* **** & $\mathrm{s}^{*} * \mathrm{a} \mathrm{t} * \mathrm{r}$ & ewrtase \\
\hline helmet & hel $* * *$ & $* * 1 \mathrm{~m} * \mathrm{t}$ & lhetem \\
\hline shrimp & $\operatorname{shr} * * *$ & $* \mathrm{~h}^{*} \mathrm{i} \mathrm{m} *$ & phrism \\
\hline laundry & lau $* * * *$ & $* \mathrm{a} * \mathrm{ndr} *$ & arlundy \\
\hline bacteria & $\mathrm{bac} * * * * *$ & $* \mathrm{ac} * * \mathrm{r} * \mathrm{a}$ & cataribe \\
\hline mushroom & mus $* * * * *$ & $* \mathrm{us}^{*} \mathrm{r}^{*} \mathrm{o} *$ & momusroh \\
\hline monster & $\operatorname{mon} * * * *$ & $* \mathrm{on}^{*} \mathrm{t} \mathrm{e}^{*}$ & sternom \\
\hline battery & bat $* * * *$ & $\mathrm{~b} * \mathrm{t} * \mathrm{er} *$ & betytar \\
\hline lobster & $\mathrm{lob} * * * *$ & $10^{*} \mathrm{~s}^{*} \mathrm{e}^{*}$ & lerstob \\
\hline cottage & $\cot * * * *$ & $*_{\mathrm{ot}} * \mathrm{ag} *$ & tagteoc \\
\hline husband & hus $* * * *$ & $\mathrm{~h}^{*} \mathrm{~s}^{*} \mathrm{an} *$ & budhans \\
\hline criminal & $\operatorname{cri} * * * * *$ & $* \mathrm{r} * \mathrm{~m} * \mathrm{n} \mathrm{a} *$ & nicramil \\
\hline bishop & bis $* * *$ & $\mathrm{~b} * \mathrm{~s} * \mathrm{o} *$ & shopib \\
\hline stadium & $\mathrm{sta}^{* * * *} *$ & $\mathrm{~s}^{*} \mathrm{ad} * \mathrm{u} *$ & matisud \\
\hline penguin & pen $* * * *$ & $* \mathrm{e}^{*} \mathrm{~g} *$ in & nunipeg \\
\hline breeze & bre $* * *$ & $\mathrm{~b}^{*} \mathrm{e}^{*} \mathrm{z} *$ & zeereb \\
\hline diamond & $\operatorname{dia} * * * *$ & $*$ i a $*$ on $*$ & dandimo \\
\hline bucket & buc $* * *$ & $* \mathrm{u} * \mathrm{k} \mathrm{e}^{*}$ & ckuteb \\
\hline avalanche & ava $* * * * * *$ & $* \mathrm{va}^{*} * \mathrm{n} \mathrm{c} * \mathrm{e}$ & leavachan \\
\hline cucumber & $\operatorname{cuc} * * * * *$ & $\mathrm{c}^{* *} \mathrm{um} * \mathrm{e}^{*}$ & becrumuc \\
\hline barrel & bar $* * *$ & $\mathrm{~b} * \mathrm{r} * * 1$ & lerbar \\
\hline tobacco & tob $* * * *$ & $\mathrm{t}^{* *} \mathrm{a} \mathrm{c}^{* *}$ & cotcoab \\
\hline squirrel & squ $* * * * *$ & $\mathrm{~s} * * \mathrm{i} * \mathrm{r} \mathrm{e}^{*}$ & rilqsure \\
\hline ambulance & $\mathrm{amb}^{* * * * * *}$ & $\mathrm{a}^{* * \mathrm{u} * \mathrm{a} * \mathrm{c} *}$ & balecnuma \\
\hline sparrow & $\mathrm{spa} * * * *$ & $* \mathrm{pa} * \mathrm{r} * \mathrm{w}$ & srawrop \\
\hline grocery & gro $* * * *$ & $\mathrm{~g}^{*} \mathrm{o} * * \mathrm{r} *$ & croregy \\
\hline lettuce & let $* * * *$ & $*$ et $* \mathrm{u} \mathrm{c}^{*}$ & cutelut \\
\hline sidewalk & $\operatorname{sid} * * * * *$ & $\mathrm{~s}^{*} \mathrm{~d} * * \mathrm{a} \mathrm{l}^{*}$ & awksield \\
\hline garage & $\operatorname{gar} * * *$ & $\mathrm{~g} * \mathrm{ra} * *$ & aregag \\
\hline shelter & she $* * * *$ & $* \mathrm{~h} * \mathrm{l} * \mathrm{e} \mathrm{r}$ & lertesh \\
\hline$\underline{\text { tornado }}$ & tor $* * * *$ & $\mathrm{t}^{*} \mathrm{rn} * \mathrm{~d}^{*}$ & daroton \\
\hline
\end{tabular}




\subsection{Procedure}

An independent variable of visually primed and non-primed words was put under scrutiny on 3 different testing conditions. Also the gender was investigated in each group separately as another independent variable. After selecting the participants, the target words were selected to be used for different phases of the study. In order to conduct the study, 30 words were needed both for the treatment phase and for test developing phase and one extra word to create an example for directing the participants. The guidelines used for target words' selection were derived from previous studies (e.g., Soler, Dasí \& Ruiz, 2015). Classically, word reading has been used as an ideal priming tool mainly because it is quick and easy to perform and accordingly, this speed performance would minimize the conscious recollection (MacLeod, 2008).

For determining the study's target words, words of medium length (between 6 to 9 letters, the most common word length in English) were selected. These words did not have any of their three first letters in common and they were all concrete nouns (the most frequent syntactic category of English words). As Nation (1990) mentioned, around $95 \%$ of oral and written English texts are comprised of 5000 most frequent words. Hence, the study's target words which were more or less at the same level of frequency, were randomly selected from $A$ Frequency Dictionary of Contemporary American English by Davis and Gardner (2010) which listed the 5000 most frequent words and their collocates based on The Corpus of Contemporary American English (COCA) which is the largest corpus of American English. 15 words were used as the words that learners were exposed to prior to the tasks and another 15 words were only included in the tasks as non-studied words, words that they have not encountered in the first phase. So, each task contained 30 items, 15 items previously used as primes in the first phase of the study and another 15 words not shown to participants in the first phase. One extra word was used to create an example of a solved WSC, WFC and anagram solution items to show participants how the tasks had to be done.

For the priming phase, Microsoft PowerPoint software was used to show the target 15 words' orthographies and images on consecutive slides. These words were primed visually with the same typeface, color, font size and picture size on the blank screen for three seconds one after another with 2-second intervals. This phase took less than two minutes. As the words were presented only for a short period of time and then disappeared, the participants were told not to turn their heads and pay attention to the appearance of the words one by one. The words used on the slides were the same for the three groups. However, they were not told that they were going to be tested on these words. Their unawareness of the upcoming tasks, helped minimize participants' conscious analysis of the incident. Afterwards, the participants had to do a distracter task in a 15 minute break. They had to name and debate on the best movie they have ever watched. The distracter task would also help distract 
participants' minds away from the primed words, separating the priming phase and the task phase.

Then for the assessment phase, after a short break the participants were given the implicit memory tasks of WSC, WFC or anagram solution tasks depending on the experimental groups. The items were presented visually with the same typeface, color and font size on the blank screen. Before answering the questions, participants read the instructions on how to do the tasks. Moreover, in order to avoid misunderstandings, the instructions were also explained orally and then one example was done to clarify the procedure. For each item, they were given 10 seconds to write down the answer on blank answer sheets. This time limit was set so that respondents answered with what crossed their minds first, without much conscious analysis. Depending on their group, the participants either did a WFC task, WSC task or an anagram solution task. After 10 seconds allocated to answer each item followed by a 2 -second blank interval, they were shown the next item. This procedure went on until the last item was done. For the three groups the procedure was the same and only the tasks that they had to do were different. The estimated time for the whole experimental session was 10 minutes.To avoid the sensitivity of the participants, the two groups of primed and non-primed items were randomly accomodated in the test items of the three tasks. It should be mentioned that in WFC and anagram solution tasks, the items had only one possible solution, however, in WSC task, some of the items could have more than one answer. Therefore, in case of the primed items, only those answers which were the same as the primed prompts were considered to be acceptable, however, these cases were very rare (to be exact three out of 45) and not statistically meaningful. The data collection phase took two months to complete.

\section{Results and Discussion}

\subsection{Results}

For answering the first research question, a paired-samples t-test had to be run for each of the three implicit memory tasks (WSC, WFC and anagram solution) separately to see if the experimental intervention had influenced the scores in favor of the primed items. The result of the normality test run for the primed and non-primed items for the WSC task could be found in Table 2.

Table 2. Tests of normality for WFC task.

\begin{tabular}{|l|c|c|c|}
\hline \multirow{2}{*}{} & \multicolumn{3}{|c|}{ Kolmogorov-Smirnov } \\
\cline { 2 - 4 } & Statistic & df & Sig. \\
\hline Primed & .157 & 30 & .057 \\
\hline Non-primed & .177 & 30 & .077 \\
\hline
\end{tabular}


As discernible, the scores of the primed and non-primed items were normally distributed. Table 3 shows the results of the t-test for the primed and the non-primed lexical items on the WSC task.

Table 3. Paired-samples t-test for WSC task.

\begin{tabular}{|c|c|c|c|c|c|c|}
\hline \multicolumn{7}{|c|}{ Paired Differences } \\
\hline & Mean & SD & Std. Error Mean & df & t & Sig. (2-tailed) \\
\hline Primed/Non-primed & 2.068 & 2.153 & .3999 & 29 & 5.174 & $.000^{*}$ \\
\hline
\end{tabular}

According to the Table 3, there was a statistically significant difference between the scores of the participants on primed and non-primed items (sig. $=0.000<0.05$ ) meaning that the priming intervention had influenced the primed items results positively. The primed items on the WSC have yielded a higher mean ( $M=10.51$, $\mathrm{SD}=1.50)$ in comparison with the non-primed items $(\mathrm{M}=8.44, \mathrm{SD}=1.59)$. The effect size was also calculated for the result of this comparison (0.48). Similarly normality test was run for the scores obtained on the WFC task (Table 4); the scores of the two categories of primed and non-primed lexical items had been normally distributed. The data were also checked for any possible outliers.

Table 4. Tests of normality for WFC task.

\begin{tabular}{|l|c|c|c|}
\hline \multirow{2}{*}{} & \multicolumn{3}{|c|}{ Kolmogorov-Smirnov } \\
\cline { 2 - 4 } & Statistic & df & Sig. \\
\hline Primed & .160 & 30 & .048 \\
\hline Non-primed & .143 & 30 & .120 \\
\hline
\end{tabular}

The paired-samples t-test then was run for the WFC task.

Table 5. Paired-samples test for WFC task.

\begin{tabular}{|c|c|c|c|c|c|c|}
\hline \multicolumn{7}{|c|}{ Paired Differences } \\
\hline & Mean & SD & Std. Error Mean & df & t & Sig. (2-tailed) \\
\hline Primed/Non-primed & 3.500 & 2.063 & .3767 & 29 & 9.290 & $.000^{*}$ \\
\hline
\end{tabular}

Table 5 indicates that a significant difference existed between the participants' performance on primed and non-primed items (sig. $=.000<.05$ ); the primed items had higher scores $(M=9.00, S D=1.41)$ than non-primed items $(M=5.5, S D=1.79)$ with the effect size of (0.74). Finally, anagram solution task data were analyzed and checked for normality and possible outliers as shown in Table 6.

Table 6. Tests of normality for anagram solution task.

\begin{tabular}{|l|c|c|c|}
\hline \multirow{2}{*}{} & \multicolumn{3}{|c|}{ Kolmogorov-Smirnov } \\
\cline { 2 - 4 } & Statistic & df & Sig. \\
\hline Primed & .152 & 30 & .076 \\
\hline Non-Primed & .139 & 30 & .142 \\
\hline
\end{tabular}


A paired-samples t-test was then conducted on the data to assess the effect of priming on the participants' performance on the anagram solution task. Table 7 illustrates a statistically significant difference observed between scores on primed and non-primed items. Participants did better on primed items $(M=11.63, \mathrm{SD}=1.73)$ than on non-primed items $(\mathrm{M}=7.26, \mathrm{SD}=2.31)$. This comparison had the effect size of 0.79 .

Table 7. Paired-samples test for anagram solution task.

\begin{tabular}{|c|c|c|c|c|c|c|}
\hline \multicolumn{7}{|c|}{ Paired Differences } \\
\hline & Mean & SD & Std. Error Mean & df & t & Sig. (2-tailed) \\
\hline Primed/Non-primed & 4.366 & 2.266 & .413 & 29 & 10.553 & $.000^{*}$ \\
\hline
\end{tabular}

Statistical analyses revealed that for all the three groups, there existed significant differences between the mean scores of the primed and non-primed lexical items. Moving on to the second research question, the results of the primed items of the three tasks had to be compared in order to see which task had been more influenced by the intervention. For this comparison, a one way ANOVA had to be done to determine if there was a significant difference between the mean scores of the three tasks on the primed items. Before that, the homogeneity of variance assumption was checked through Levene's test. The ANOVA showed that there was a statistically significant difference between the tasks regarding the score on the primed items (sig. $=.000<.05)$.

Table 8. ANOVA to compare WSC, WFC and anagram solution priming scores.

\begin{tabular}{|l|c|c|c|c|c|}
\hline \multicolumn{1}{|c|}{ Source } & Sum of Squares & df & Mean Square & F & Sig. \\
\hline Between Groups & 104.956 & 2 & 52.478 & 21.904 & .000 \\
\hline Within Groups & 208.433 & 87 & 2.396 & & \\
\hline Total & 313.389 & 89 & & & \\
\hline
\end{tabular}

However a post-hoc-test had to be conducted in order to further explore where exactly the difference had occurred. Table 9 provides multiple comparisons of the post-hoc Tukey test.

Table 9. Multiple comparisons.

\begin{tabular}{|c|c|c|c|c|c|c|}
\hline \multicolumn{7}{|c|}{ Dependent Variable: Primed Scores } \\
\hline \multirow{2}{*}{$\begin{array}{c}\text { Task } \\
\text { Groups }\end{array}$} & \multirow{2}{*}{$\begin{array}{l}\text { Task } \\
\text { Groups }\end{array}$} & \multirow{2}{*}{$\begin{array}{c}\text { Mean } \\
\text { Difference }\end{array}$} & \multirow[b]{2}{*}{ SD } & \multirow[b]{2}{*}{ Sig. } & \multicolumn{2}{|c|}{$95 \%$ Confidence Interval } \\
\hline & & & & & $\begin{array}{l}\text { Lower } \\
\text { Bound }\end{array}$ & $\begin{array}{l}\text { Upper } \\
\text { Bound }\end{array}$ \\
\hline \multirow[t]{2}{*}{ 1-stem } & 2- fragment & 1.53333 & .39965 & $.001^{*}$ & .5804 & 2.4863 \\
\hline & 3- anagram & -1.10000 & .39965 & $.020^{*}$ & -2.0530 & -.1470 \\
\hline \multirow[t]{2}{*}{ 2- fragment } & 1 - stem & -1.53333 & .39965 & $.001^{*}$ & -2.4890 & -.5864 \\
\hline & 3- anagram & -2.63333 & .39965 & $.000^{*}$ & -3.5863 & -1.6804 \\
\hline \multirow[t]{2}{*}{ 3- anagram } & 1 - stem & 1.10000 & .39965 & $.020^{*}$ & .1470 & 2.0530 \\
\hline & 2- fragment & 2.63333 & .39965 & $.000^{*}$ & 1.6804 & 3.5863 \\
\hline
\end{tabular}

*. The Sig. is significant at the 0.05 level. 
Multiple comparisons revealed that the performance of the participants in WSC $(M=10.53, S D=1.47)$, WFC $(M=9, S D=1.41)$ and anagram solution tasks $(M=11.63$, $\mathrm{SD}=1.73$ ) were significantly different from each other. The third research question required a comparison between male and female participants in terms of their performance on primed items. Hence, three sets of independent-samples t-tests were conducted for each task separately to see if there was a significant difference between the male and female participants with respect to gender as an independent variable. Before running the t-tests for priming scores the data normality was approved. As it can be seen in Table 10 the sig. value was reported as 0.63 implying that there was no significant difference between males $(M=10.66, S D=1.49)$ and females $(M=10.64$, $\mathrm{SD}=1.33)$ in their performance on the primed lexical primed items.

Table 1o. Independent samples t-test for comparing males and females on WSC primed items.

\begin{tabular}{|l|c|c|c|c|c|c|c|}
\hline \multicolumn{3}{|c|}{$\begin{array}{c}\text { Levene's Test for Equality of } \\
\text { Variances }\end{array}$} & \multicolumn{5}{c|}{ T-test for Equality of Means } \\
\hline $\begin{array}{l}\text { Equal variances } \\
\text { assumed }\end{array}$ & $\mathrm{F}$ & Sig. & $\mathrm{t}$ & $\mathrm{df}$ & $\begin{array}{c}\text { Sig. }(2- \\
\text { tailed) }\end{array}$ & $\begin{array}{c}\text { Mean } \\
\text { Differences }\end{array}$ & $\begin{array}{c}\text { Std. Error } \\
\text { Difference }\end{array}$ \\
\cline { 2 - 8 } & .008 & .930 & .48 & 28 & .630 & .266 & .547 \\
\hline
\end{tabular}

Another independent-samples t-test was conducted on priming scores of males and females on word fragment completion (WFC) task after the obtained data were checked for normality and outliers. Levene's test indicated that the assumption of equality of variances was not violated. Results of the independent-samples t-test showed that the performance of males $(M=8.7, S D=1.48)$ and females $(M=9.2$, $\mathrm{SD}=1.33$ ) did not significant differ (sig. $=0.31)$.

Table 11. Independent-samples t-test for comparing males and females on WFC priming.

\begin{tabular}{|l|c|c|c|c|c|c|c|}
\hline \multicolumn{2}{|c|}{$\begin{array}{c}\text { Levene's Test for Equality of } \\
\text { Variances }\end{array}$} & \multicolumn{5}{c|}{ T-test for Equality of Means } \\
\hline $\begin{array}{l}\text { Equal variances } \\
\text { assumed }\end{array}$ & $\mathrm{F}$ & Sig. & $\mathrm{t}$ & $\mathrm{df}$ & $\begin{array}{c}\text { Sig. (2- } \\
\text { tailed) }\end{array}$ & $\begin{array}{c}\text { Mean } \\
\text { Differences }\end{array}$ & $\begin{array}{c}\text { Std. Error } \\
\text { Difference }\end{array}$ \\
\cline { 2 - 8 } & .234 & .633 & - & 28 & .31 & -.533 & .515 \\
\hline
\end{tabular}

The third and the last independent-samples t-test was conducted to compare performance of males and females on primed items in the anagram solution task. First, the scores were tested for normality and existence of outliers. The KolmogolovSmirnov normality test confirmed normality for priming scores of males and females. Tables 12 revealed that no significant difference was observed in the performance of males $(M=11.93, S D=1.57)$ and females $(M=11.33, S D=1.87)$ on primed items in the anagram solution task (sig. $=0.352$ ). 
Table 12. Independent-samples t-test for comparing males and females on anagram solution task.

\begin{tabular}{|l|c|c|c|c|c|c|c|}
\hline \multicolumn{3}{|c|}{$\begin{array}{c}\text { Levene's Test for Equality of } \\
\text { Variances }\end{array}$} & \multicolumn{6}{c|}{ T-test for Equality of Means } \\
\hline $\begin{array}{l}\text { Equal variances } \\
\text { assumed }\end{array}$ & $\mathrm{F}$ & Sig. & $\mathrm{t}$ & $\mathrm{df}$ & $\begin{array}{c}\text { Sig. (2- } \\
\text { tailed) }\end{array}$ & $\begin{array}{c}\text { Mean } \\
\text { Differences }\end{array}$ & $\begin{array}{c}\text { Std. Error } \\
\text { Difference }\end{array}$ \\
\cline { 2 - 8 } & .682 & .416 & .947 & 28 & .352 & .600 & .633 \\
\hline
\end{tabular}

\subsection{Discussion}

This study employed positive priming technique to check the retrieval of the English language lexical items on three implicit memory tasks of WFC, WSC and anagram solution. Positive priming is thought to be caused by spreading activation to parts of a particular association in memory just before carrying out an action or task (Harley, 2009). The priming type which was utilized in this investigation was of perceptual type which is based on the appearance of the stimulus and is enhanced by the match between the early and later prompts. Perceptual priming decreases neural processing in the cerebral cortex of sensory stimuli with stimulus exposure. This reduction is due to representational sharpening in the early sensory areas which reduces the number of neurons representing the stimulus. This leads to a more selective activation of neurons representing objects in higher cognitive areas (Harley, 2009).

This study indicated that priming as an intervention have positively affected participants' performance on the items they had been exposed to during the priming phase. The results are in agreement with Rajarm and Roediger (1993) also reported a better performance for the primed words than non-primed words through lexical repetition priming on WFC, WSC and anagram solution. The study's findings also support what Altarriba and Knickerbocker (2011) found. They studied priming in a foreign language learning context and reported positive effects on vocabulary acquisition. This means that stimulus exposure will lead to the stimulation of neural plasticity which would change neural activity in reaction to the same stimulus (GrillSpector, Henson \& Martin, 2006) hence, the existence of visual priming also has a clinical proof.

The ANOVA test showed that the participants' best retrieval happened on the anagram solution task while the poorest retrieval was observed for WFC task. This is in line with Jacoby (1983) who concluded that WFC tasks are best performed when the target words are assessed in context not in isolation when perceptually primed. In another study, Cohen and Squire (1989) had compared anagram solution and WFC tasks and found a lower mean score for anagram solution than WFC task in contrast with the present research. On the other hand, Rajarm and Roediger (1993) who compared different priming modalities in word identification, WSC, WFC and 
anagram solution tasks reported the a highly positive effect of priming for all the implicit tasks similarly particularly for anagram solution tasks. In a more recent study Mielke and Hume (2001) showed that the initial letters of the words are considered to play a significant role in accessing lexical information and when that part is missing this access is hampered, consequently, WFC could be considered as one the most difficult implicit memory tasks, what is implied by the findings of this study.

The findings also showed that in any of the experimental groups, no significant difference was observed between male and female participants. This piece of finding is in line with Simotas (1996), Halpern (1992) and Fausto-Sterling (1985) who argued for the equality of both genders' ability for the successful performance of implicit memory tasks. This study may also support Feingold's (1994) point of view that gender differences in memory issues might be either the result of social or biological factors not the cognitive ones. Another study by Herlitz, Nilsson and Bäckman (1997), showed no statistically-significant difference between men and women in visual priming effects of WSC and WFC tasks.

Research in this area is very sparse and seems restricted to studies of explicit memory tasks. Lorenzi et al. reserach (2006) is one of the few studies which has focused on the gender differences on implicit memory task performance. Contrary to the present study, they observed that women performed better on the WSC task than men and associated their findings to the cognitive superiority of women over men on performing conscious tasks.

\section{CONCLUSION}

In order to observe the potential effects of priming on retrieval and production of lexical items, three experimental groups were recruited to be compared on the three implicit memory tasks of WSC, WFC and anagram solution. Results reported the superiority of primed items than non-primed ones for all the three implicit memory tasks. It was also demonstrated that anagram solution, WSC and WFC had yielded the highest scores, respectively. Moreover, no significant difference found between male and female participants in any of the implicit memory tasks. However, further research studies would be appreciated regarding the effectiveness of priming in pedagogic contexts as foreign language lexis retrieval is concerned.

This study may also provide some insights regarding foreign language vocabulary learning and teaching. Visual priming can be considered as a complementary aid in stimulating learners to produce vocabulary items they have already learned. As stated by Kircher, Smith, Lockhart, King and Jain (2010), visual priming can be employed to maximize retention and minimize the teaching and learning time. Moreover, visual priming can create long-lasting memory effect (Hearley, 2009) and would help with retrieval of the physical features of the words such as visual appearance, pronunciation or the orthography (Khodadady \& Khaghaninejad, 2013). 


\section{REFERENCES}

Altarriba, J. \& Knickerbocker, H. (2011). Acquiring second language vocabulary through the use of images and words. In K. M. P. Trofimovich (Ed.), Applying priming methods to L2 learning, teaching and research (pp. 21-48). Amsterdam: John Benjamins.

Bird, S. A. \& Williams, J. N. (2002). The effect of bimodal input on implicit and explicit memory: An investigation into the benefits of within-language subtitling. Applied Psycholinguistics, 23(4), 509-533.

Brown, R., Waring, R. \& Donkaewbua, S. (2008). Incidental vocabulary acquisition from reading, reading-while-listening, and listening to stories. Reading in a Foreign Language, 20, 136-163.

Cattell, J. M. (1886). The time taken up by cerebral operations. Mind, 11(3), 377-399.

Cervantes, H. I. D. E. \& Granados Ramos, D. A. G. (2015). Gender differences in word fragment and word stem completion memory tasks. Interamerican Journal of Psychology, 49(3), 285-293.

Cohen, N. J. \& Squire, L. R. (1989). Preserved learning and retention of patternanalyzing skill in amnesia: Dissociation of knowing how and knowing that. Science, 210, 207-210.

Cleeremans, A. (2009). Implicit learning and implicit memory. In W. P. Banks (Ed.), Encyclopedia of consciousness (pp. 369-381). Elsevier: Academic Press.

Davis, M. \& Gardner, D. (2010). A frequency dictionary of contemporary American English word sketches, collacates, and thematic lists. London: Routledge.

Dawei, W., Jinbo, X. \& Heping, W. (2016). The English past tense debate in the Chinese EFL learners' mind: A masked priming study. Chinese Journal of Applied Linguistics, 39(2), 185-198.

Fausto-Sterling, A. (1985). Myth of gender: Biological theories about women and men. New York: Basic Books, Inc.

Feingold, A. (1994). Gender differences in personality: A meta-analysis. Psychological bulletin, 116(3), 429-456.

Grill-Spector, K., Henson, R. \& Martin, A. (2006). Repetition and the brain: Neural models of stimulus-specific effects. Trends Cogn Sci, 10(1), 14-23.

Gulan, T. \& Valerjev, P. (2010). Semantic and related types of priming as a context in word recognition. Review of Psychology, 17(1), 53-58. 
Halpern, D. F. (1992). Sex differences in cognitive abilities (2nd ed.). Hillsdale, NJ: Lawrence Erlbaum Associates.

Harley, T. (2009). Psychology of language: From data to theory. Madrid: McGraw-Hill.

Henson, R. N. \& Rugg, M. D. (2003). Neural response suppression, haemodynamic repetition effects, and behavioural priming. Neuropsychologia, 41(3), 263-270.

Herlitz, A., Nilsson, L.-G. \& Bäckman, L. (1997). Gender differences in episodic memory. Memory \& Cognition, 25(6), 801-811.

Jacoby, L. L. (1983). Remembering the data: Analyzing interactive processes in reading. Journal of Verbal Learning \& Verbal Behavior, 22, 485-508.

Jiang, L. \& Huang, K. (2015). The efficacy of structural priming on the acquisition of double object construction by Chinese EFL learners. Higher Education Studies, 5(5), 38-49.

Khodadady, E. \& Khaghaninejad, M. S. (2013). Acquisition of French polysemous vocabularies: Translation-based or schema-based instruction? Porta Linguarum, 19, 26-41.

Kircher, K., Smith, M. C., Lockhart, R. S., King, M. L. \& Jain, M. (2010). The bilingual lexicon: Language-specific units in an integrated network. Journal of Verbal Learning and Verbal Behavior, 23(4), 519-539.

Lemm, K. M., Dabady, M. \& Banaji, R.M. (2005). Gender picture priming: It works with denotative and connotative primes. Social cognition, 23(3), 218-241.

Lorenzi, I., Giunta, F. \& Di Stefano, M. (2006). Implicit and explicit memory formation: Influence of gender and cultural habits. Archives Italiennes de Biologie, 144(1), 25-31.

MacLeod, C. M. (2008). Half a century of research on the Stroop effect: An integrative review. Psychological bulletin, 109(2), 163-203.

Masson, M. (2001). Cognitive psychology of priming. In N. Smelser \& P. Baltes. (Eds.), International Encyclopedia of the Social \& Behavioral Sciences (pp. 1204212046). Oxford: Elsevier.

McDonough, K. (2006). Interaction and syntactic priming: English L2 speakers production of dative constructions. Studies in second language acquisition, 28(2), 179-207.

McDonough, K. \& Mackey, A. (2008). Syntactic primimg and question development. Studies in second language acquisition, 30(3), 31-47. 
McDonough, K. \& Chaikitmongkol, W. (2010). Collaborative syntactic priming activities and EFL learners' production of wh-questions. Canadian Modern Language Review, 66(6), 817-841.

Mielke, S. \& Hume, A. (2001). Negative priming as a memory phenomenon: A review of 20 years of negative priming research. Journal of Psychology, 215(1), 35-5.

Meyer, D. E. \& Schvaneveldt, R. (1971). Facilitation in recognizing pairs of words: Evidence. Journal of Experimental Psychology, 90, 227-234.

Nation, P. (1990). Learning vocabulary in another language. Cambridge: Cambridge University Press.

Oschner, K. N., Chiu, C. Y. \& Schacter, D. L. (1994). Varieties of priming. Opinion in Neurobiology, 4(2), 189-194.

Perruchet, P. \& Baveux, P. (1989). Correlational analyses of explicit and implicit memory performance. Memory \& Cognition, 17(1), 77-86.

Rajarm, S. \& Roediger, H. (1993). Direct comparison of four implicit memory tests. Journal of Experimental Psychology: Learning, Memory, and Cognition, 19(4), 765-776.

Schacter, D. L. (1987). Effects of etaborative processing on implicit and explicit memory for new associations. Journal of Experimental Psychology: Learning, Memory, and Cognition, 12, 432-444.

Segal, S. J. \& Cofer, C. N. (1960). The effect of recency and recall on word association. American Psychologist, 15, 451-463.

Shen, L. (2015). Study on the effect of structural priming on Chinese EFL learners' language production. Theory and Practice in Language Studies, 5(12), 2591-2598.

Simotas, S. (1996). Effect of gender and age on perceptual and conceptual implicit memory. Unpublished master's thesis, The University of Montana, Montana, USA.

Soler, M., Dasí, C. \& Ruiz, J. (2015). Priming in word stem completion: Comparison with previous results in word fragment completion tasks. Frontiers in Psychology, 6, 11-72.

Srinivas, K. \& Roediger, H. L. (1990). Classifying implicit memory tests: Category association and anagram solution. Journal of Memory and Language, 29(4), 389412.

Trofimovich, P. \& McDonough, K. (2011). Using priming methods to study L2 learning and teaching. Amsterdam/Philadelphia: John Benjamins. 
Yamada, Y. (2015). Gender and age differences in visual perception of patterns randomness. Science Post-print, 1(2), 24-41. 